\title{
Ultrastructural features and prevalence of tubuloreticular structures in the ocular vasculature of patients with AIDS: a study of 23 cases
}

\author{
Raj K Maturi, Ramon L Font
}

\begin{abstract}
Background-Tubuloreticular structures (TRS) are subcellular inclusions that are most commonly found in endothelial cells and lymphocytes of patients with autoimmune or collagen vascular disorders. In AIDS, TRS have been described in various tissues throughout the body including the lung, kidney, liver, muscle, and skin.

Methods-Ocular tissues from 23 patients with AIDS were examined by electron microscopy. These included 17 postmortem eyes in addition to three chorioretinal and three conjunctival biopsy specimens.
\end{abstract}

Results-The overall prevalence of TRS in the ocular and conjunctival endothelial cells was found to be $83 \%(19 / 23)$.

Conclusions-This is the first documented study of the prevalence of these structures in the ocular structures of patients with AIDS. Given the high frequency of their occurrence in AIDS, it is recommended that the presence of TRS in ocular or conjunctival tissues be an indication for obtaining an HIV antibody titre. Additionally, a rheumatological examination for HIV seronegative patients is suggested. (Br f Ophthalmol 1996; 80: 252-255)

Tubuloreticular structures (TRS) were first described in association with systemic lupus erythematosus (SLE) ${ }^{1}$ but have been found in association with other immunological disorders, ${ }^{2-4}$ including AIDS $^{5-9}$ and, rarely, malignant lymphomas and leukaemias. ${ }^{10}$ Ultrastructurally, TRS are composed of multiple branching inclusions located adjacent to the cisternae of the rough surfaced endoplasmic reticulum and, occasionally, within the perinuclear envelope. ${ }^{6}$ On transmission electron microscopy, these inclusions have a diameter of $20-30 \mathrm{~nm}$ and are found most commonly as electron dense cytoplasmic aggregates. Cytochemical studies

Table 1 Prevalence of tubuloreticular structures (TRS) in 23 patients with AIDS

\begin{tabular}{|c|c|c|}
\hline A & $\begin{array}{l}17 \text { autopsy eyes. } \\
6 \text { eyes with cytomegalovirus (CMV) retinitis } \\
92 \text { eyes with no clinical or histological retinal lesions } \\
-2 \text { eyes with opportunistic infections }{ }^{\star}\end{array}$ & $\begin{array}{l}6 / 6 \text { had TRS } \\
6 / 9 \text { had TRS } \\
1 / 2 \text { had TRS }\end{array}$ \\
\hline B & $\begin{array}{l}3 \text { surgical chorioretinal biopsy specimens } \\
3 \text { eyes with clinical CMV } \\
3 \text { conjunctival biopsy specimens }\end{array}$ & $3 / 3 \mathrm{had}$ \\
\hline & $\begin{array}{l}3 \text { eyes with punctate epithelial keratoconjunctivitis } \\
\text { all prevalence of tubuloreticular structures }\end{array}$ & $\begin{array}{l}3 / 3 \text { had TRS } \\
19 / 23(83 \%)\end{array}$ \\
\hline
\end{tabular}

^Histoplasma capsulatum and Proteus sp were isolated from peripheral blood cultures (one patient each) and demonstrated in the ocular tissues by special stains. have determined that TRS consist primarily of membrane phospholipids and glycoprotein. ${ }^{23}$

An extensive review of the tissue location and cell types containing TRS in humans has been reported previously. ${ }^{10}$ One case report has described TRS in the endothelial cell of a choroidal vessel. ${ }^{11}$ One of the authors (RLF) has previously described these structures in a conjunctival biopsy specimen of an HIV seropositive patient. ${ }^{12}$

To our knowledge, no published data on the prevalence of these structures in the ocular tissues of AIDS patients have been recorded. The purpose of this study was to document the prevalence of TRS in the retinal, choroidal, and conjunctival vasculature and to demonstrate their ultrastructural features in these locations.

\section{Materials and methods}

Postmortem eyes from 17 patients who were HIV seropositive and had a diagnosis of AIDS were examined by both light and electron microscopy. Three surgical chorioretinal biopsy specimens and three conjunctival biopsy specimens were also similarly examined. Paraffin embedded $5 \mu \mathrm{m}$ sections were stained with haematoxylin and eosin, periodic acid Schiff (PAS), Gomori-methanaminesilver (GMS), and Gram methods.

For electron microscopic studies, the tissues were fixed in $10 \%$ buffered formalin, postfixed in $2 \%$ glutaraldehyde, followed by $1 \%$ osmium tetroxide. Thick sections $(\sim 1 \mu \mathrm{m})$ were stained with toluidine blue and paragon. Ultrathin sections $(40-60 \mathrm{~nm})$ were mounted on copper grids, stained with uranyl acetate and lead citrate, and examined with a Jeol 100 CX electron microscope.

We examined an average of 15 grids from each specimen, with special attention to the presence of TRS in the retinal and choroidal vasculature.

Results

The pertinent clinical findings and prevalence of TRS in 23 patients are summarised in Table 1. Nine patients who had no ocular symptoms showed no histological evidence of retinitis. All three surgical chorioretinal biopsy specimens were ophthalmoscopically diagnosed as cytomegalovirus (CMV) retinitis and were confirmed by light and electron microscopic studies. The conjunctival biopsies were performed with a presumptive diagnosis of 
microsporidial keratoconjunctivitis. In these three biopsy specimens, we found intracellular electron dense, lipoidal bodies mostly in the epithelial cells and TRS in the capillary endothelial cells. No microsporidia were identified.

We observed that eyes without TRS in the retinal capillaries also failed to demonstrate these structures in the choroidal vasculature.

Representative ultrastructural features of the TRS in the retinal and choroidal endothelial cells are illustrated in Figures 1-3. Figure 4 depicts the presence of TRS in a plasma cell

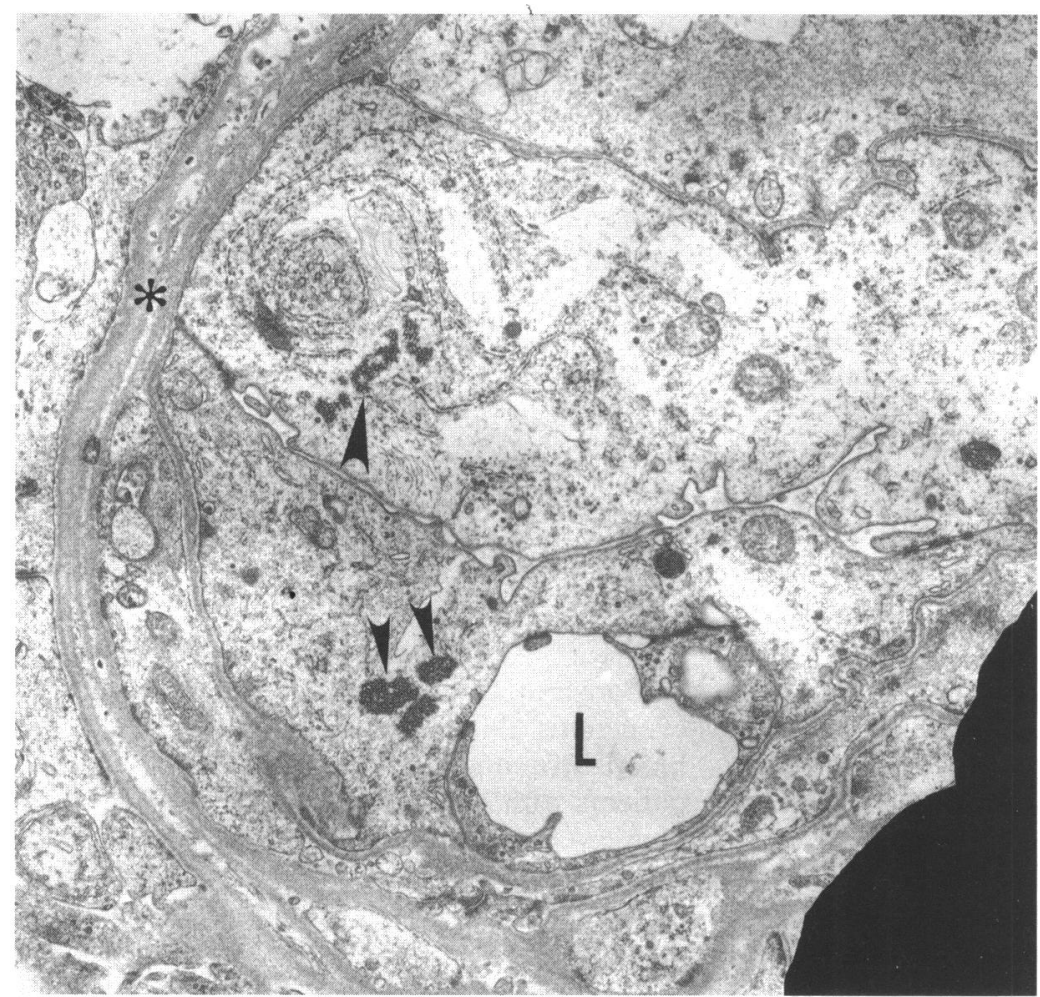

Fig $1 A$

Figure 1 (A) Low power view of retinal capillary. The endothelial cells appear swollen and the lumen $(L)$ is narrow and eccentrically displaced. Asterisk (*) outlines the basement membrane of the capillary. Several tubuloreticular structures are visible (small arrowheads). Some tubuloreticular structures appear to be merging with the rough surfaced endoplasmic reticulum (arge arrowhead) $(\times 10000)$.

(B) High power view of adjacent section of $(A)$ displaying the

tubuloreticular structures (small arrowheads). The tubuloreticular structures on the upper left appear to fuse with the adjacent lamellae of the rough surfaced endoplasmic reticulum (large arrowhead). The plasma membrane of the endothelial cell is incomplete adjacent to the tubuloreticular structures on the left. Cytoplasmic microfilaments $(F)$ $(\times 24800)$. associated with a chronic non-granulomatous choroiditis in a patient with histologically proved CMV retinitis.

\section{Discussion}

Our studies demonstrate a high prevalence of TRS in the ocular structures of patients with AIDS. Sidhu and coworkers studied 97 patients with AIDS and found a similar prevalence $(85 \%)$ of TRS in the endothelial cells from multiple anatomical sites. ${ }^{13} \mathrm{We}$ also note that TRS identified in ocular/adnexal tissues are ultrastructurally quite similar to those observed in other anatomical locations. Thus, their mechanism of formation, while still under some debate, is presumably analogous to that observed in other tissues.

Some observers have suggested that TRS may be of viral origin, ${ }^{114}$ given their close association with viral diseases. TRS are primarily composed of membrane phospholipids and glycoproteins. Evidence against a viral origin includes their lack of nucleic acids, digestion with proteases and pepsin, and insensitivity to digestion with trypsin and ribonuclease. ${ }^{1}$

The nucleoprotein strands of myxoviruses and paramyxoviruses have been confused ultrastructurally with TRS. The viral nucleocapsids of the myxovirus/paramyxoviruses have a helical configuration, are not associated with the rough surfaced endoplasmic reticulum, and rarely exceed $18 \mathrm{~nm}$ in diameter. In contrast, the tubular structures of TRS measure $20-30 \mathrm{~nm}$ in diameter and are contiguous with the endoplasmic reticulum. ${ }^{3}$

Another hypothesis regarding the origin of TRS suggests that they may be an unusual morphological response of the rough surfaced

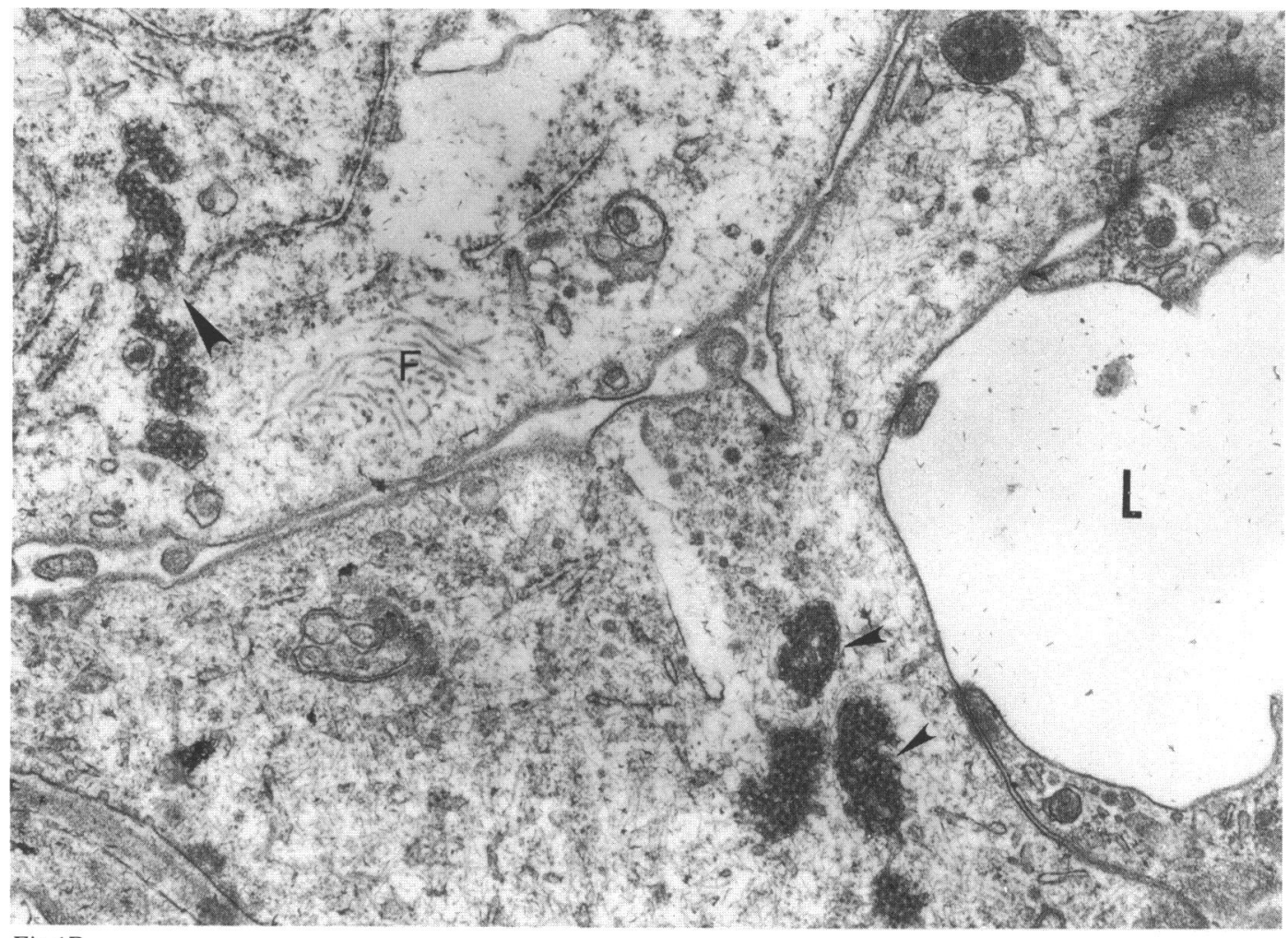




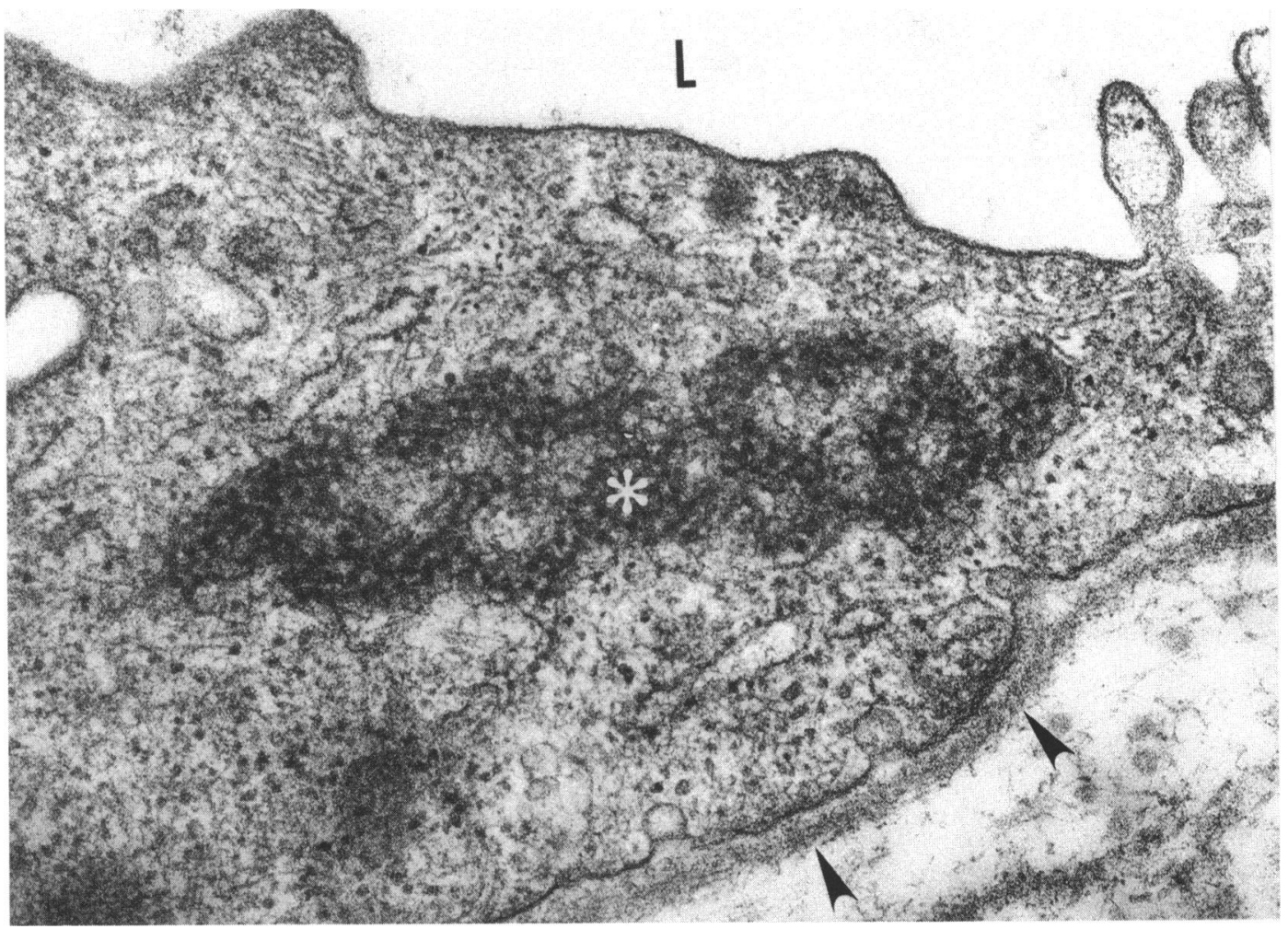

Figure 2 High power view of an endothelial cell from a retinal capillary depicting on cross section the confluent hollow tubular structures. Lumen (L) and basement membrane (arrowheads) ( $\times 58300)$.

endoplasmic reticulum occurring in cells subjected to various insults. Thus, TRS may represent a morphological expression indicative of cellular injury. ${ }^{1}$

There is significant evidence that TRS represent a cellular response to increased serum levels of interferon alfa (INF $\alpha){ }^{15-18}$ This association was first noted after the discovery that patients with systemic lupus erythematosus (SLE) had increased serum levels of
INF $\alpha .{ }^{19}$ Additionally, in vitro studies have demonstrated the induction of TRS by exogenous INF $\alpha$ when added to peripheral blood lymphocytes. ${ }^{20}$ It is noteworthy that patients with AIDS, like those with SLE, have high levels of INF $\alpha .{ }^{15}$

The presence of TRS in ocular/adnexal structures in a previously HIV seronegative patient may indicate the presence of a collagen vascular disease (typically SLE or scleroderma) or other

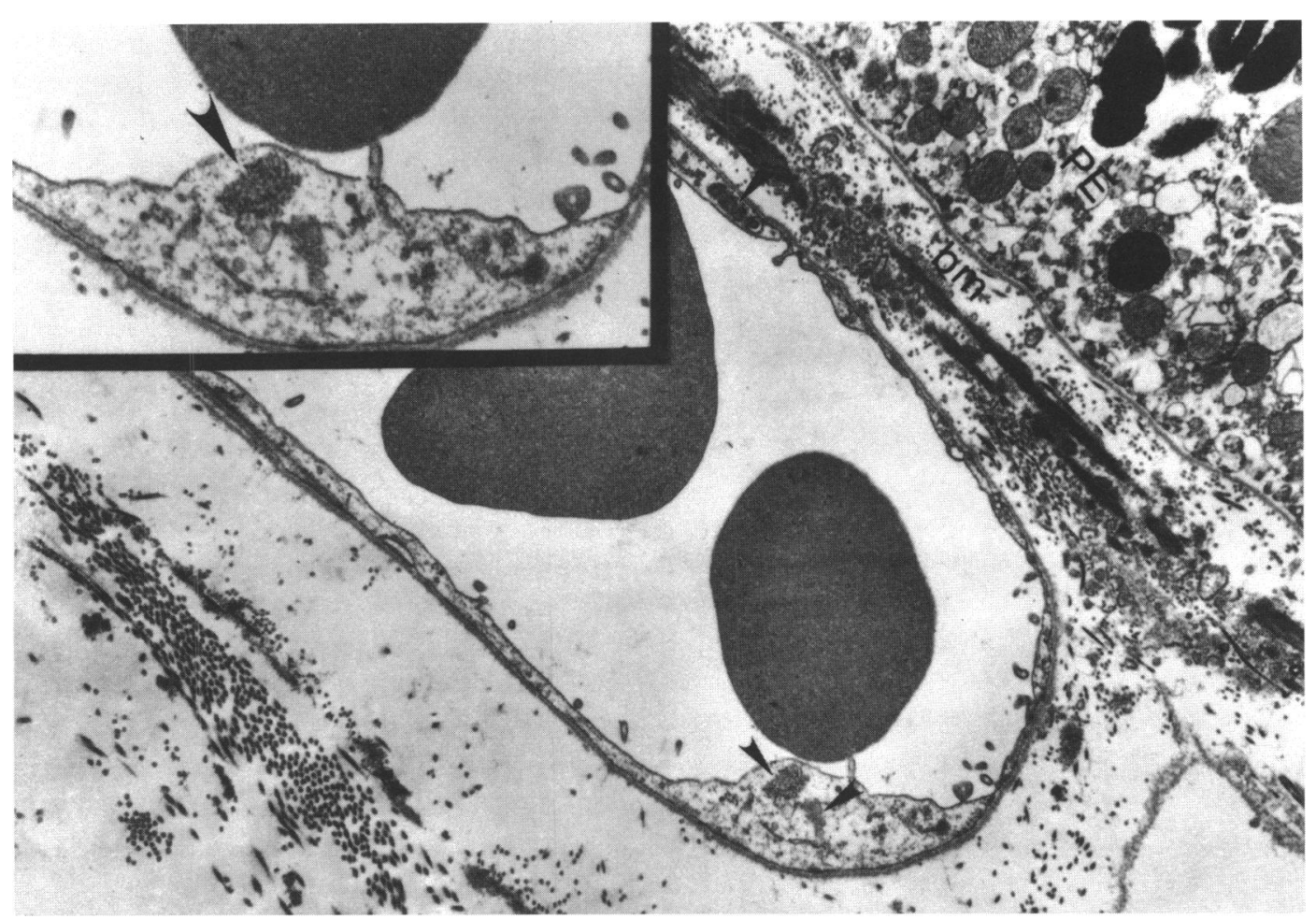

Figure 3 Low power view demonstrating several tubuloreticular structures in the endothelial cells of the choriocapillaris (arrowheads). Bruch's membrane $(\mathrm{bm})$, and retinal pigment epithelium $(P E)(\times 7800)$. Inset demonstrates a high power view of the tubuloreticular structures in the cytoplasm of the endothelial cell shown below $(\times 14350)$. 


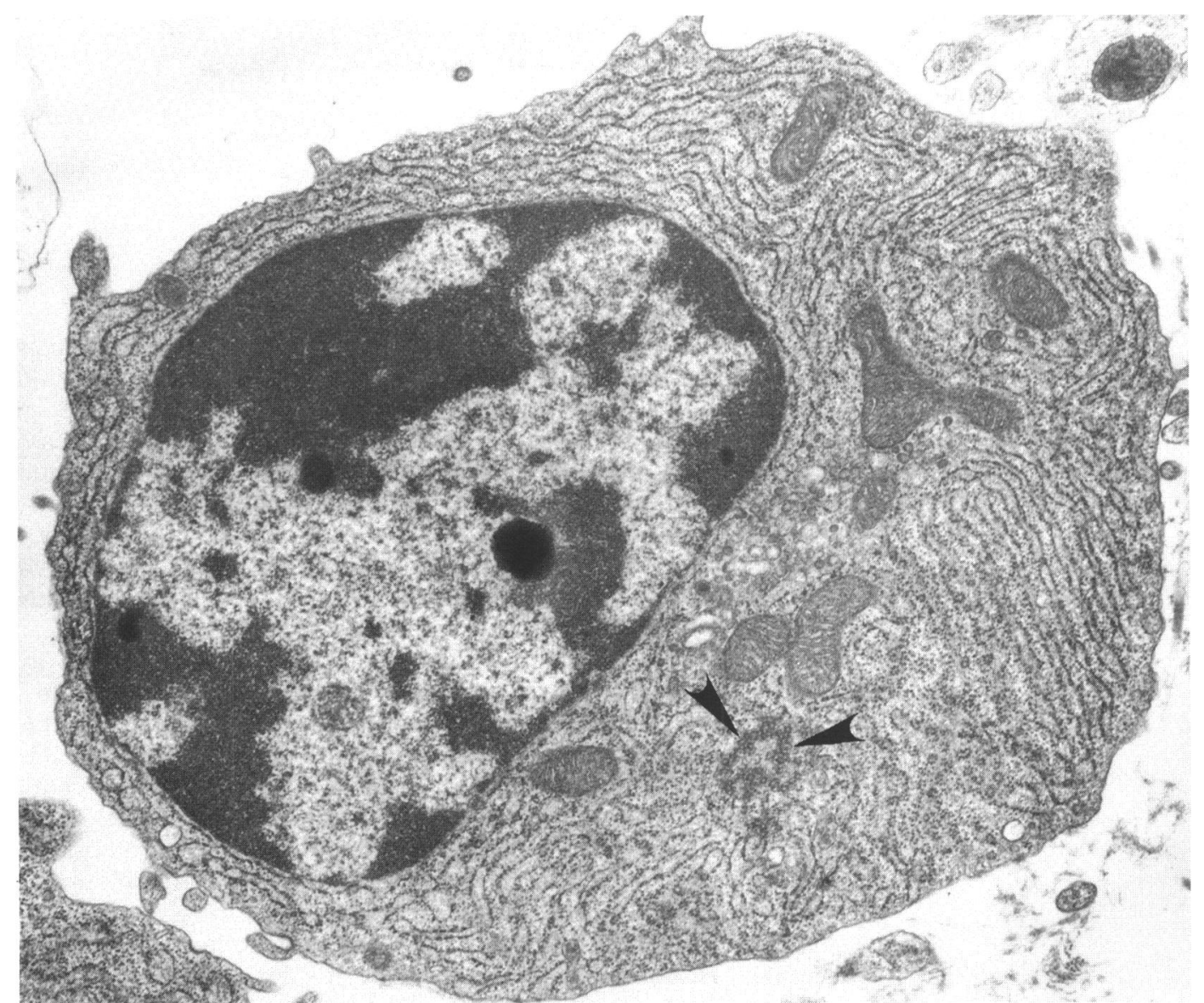

Figure 4 Chorioretinal biopsy specimen from a patient with histologically proved cytomegalovirus retinitis showing a plasma cell within the choroid. Tubuloreticular structures are demonstrated in the cytoplasm (arrowheads) $(\times 11600)$.

immunologically mediated disorders. If TRS are found in the ocular/adnexal tissues of HIV seronegative patients, we would suggest performing a complete immunological examination (antinuclear antibody, rheumatoid factor, etc) to exclude the possibility of a collagen-vascular disorder. If these results are negative, we believe that periodic HIV antibody testing is indicated to exclude the possibility that the patient might be in the prodromal stage of infection.

This study was supported in part by grants from the Retina Research Foundation and the Lions Eye Bank, Houston, Texas and the Research to Prevent Blindness, New York, USA.

1 Luu, J, Bokus D, Remington $F$, Bean $M$, Hammar $S$. Tubuloreticular structures and cylindrical confronting Tubuloreticular structures and cylindrical con

2 Fuller G, Jacobs J. Cytomembranous inclusions in the peripheral nerves in AIDS. Acta Neuropathol 1989; 79: 336-9.

3 Schaff Z, Barry DW, Grimley PM. Cytochemistry of tubuloreticular structures in lymphocytes from patients with systemic lupus erythematosus and in cultured human lymphoid cells: comparison to a paramyxovirus. Lab Invest 1973; 29: 577-85.

4 Mette SA, Palevsky HI, Pietra GG, Williams TM, Bruder E. Primary pulmonary hypertension in association with E. Primary pulmonary hypertension in association with human immunodeficiency

5 Blandshard C, Ellis DS, Tovey G, Gazzard BG. Electron microscopy of rectal biopsies in HIV-positive individuals. f Pathol 1993; 169: 79-87.

6 Mezin P, Brion J, Vermont J, Micound M, Stoebner P. Ultrastructural changes associated with peripheral neuropathy in HIV/AIDS. Ultrastruct Pathol 1991; 15: 593-602.

7 Cohen AH, Nast CC. HIV-associated nephropathy: a unique combined glomerular, tubular, and interstitial lesion. Mod Pathol 1988; 1: 87-97.

8 Chander P, Agarwal A, Soni A, Kim K, Treser G. Renal cytomembranous inclusions in idiopathic renal disease as predictive markers for the acquired immunodeficiency syndrome. Hum Pathol 1988; 19: 1060-4.
9 Kostianovsky M, Kang YH, Grimley PM. Disseminated tubuloreticular inclusions in the acquired immunotubuloreticular inclusions in the acquired immuno331-6.

10 Grimley PM, Schaff Z. Significance of tubuloreticular inclusions in the pathobiology of human diseases. Pathobiol Ann 1976; 6: 221-57.

11 Jensen OA. Cytoplasmic structures in endothelial cells of the choroid: case for the panel. Ultrastruct Pathol 1985; 8: 375-9.

12 Wilhelmus KR, Keener MJ, Jones DB, Font RL. Corneal lipidosis in patients with the acquired immunodeficiency syndrome. Am F Ophthalmol 1995; 119: 14-9.

13 Sidhu GS, Stahl RE, El-Sadr W, Cassi ND, Forrester EM, Zolla-Pazner $S$. The acquired immunodeficiency syndrome: an ultrastructural study. Hum Pathol 1985; 16: 377-86.

14 Bariety J, Amor B, Kahan A, Balfrej JL, Delbarre F. Ultrastructural anomalies in mononuclear cells of peripheral blood in SLE: presence of virus-like inclusions. Eur $\mathcal{F}$ Clin Biol Res 1971; 16: 715.

15 Orenstein JM, Preble OT, Kind P, Schulof $R$. The relationship of serum alpha-interferon and ultrastructural markers in HIV-seropositive individuals. Ultrastruct Pathol 1987; 11: 673-9.

16 Grimley PM, Davis GL, Dooley JS, Strohmaier J, Hoofnagle JH. Tubuloreticular inclusions in peripheral blood mononuclear cells related to systemic therapy with $\alpha$-interferon. Lab Invest 1985; 52: 638-49.

17 Hooks JJ, Moutsopoulos HM, Geis SA, Stahl NI, Decker $\mathrm{JL}$, Notkins AL. Immune interferon in the circulation of patients with autoimmune disease. $N$ Engl f Med 1979; patients with $5-8$.

18 Grimley PM, Rutherford MN, Kang Y, Williams T, Woody JN, Silverman RH. Formation of tubuloreticular inclusions in human lymphoma cells compared to the induction of $2^{\prime}-5^{\prime}$ oligoadenylate synthetase by leucocyte interferon in dose-effect and kinetic studies. Cancer Res 1984; 144: 3480-8.

9 Rich SA, Owens TR, Anzola CM, Bartholomew LE. Induction of lupus inclusions by sera from patients with systemic lupus erythematosus. Arthritis Rheum 1986; 29: 501-6.

20 Feldman DG, Goldstein AL, Cox DC, Grimley PM. Cultured human endothelial cells treated with recombinant leukocyte $A$ interferon (rIFN-aA). Tubuloreticular inclusion formation, anti-proliferative effect and $2^{\prime}-5^{\prime}$ inclusion formation, anti-proliferative effect and 2' 2 $^{\prime}$
oligoadenylate synthetase induction. Lab Invest 1988; 58: oligoaden 